\title{
Effect of Formulation Variables on Fabrication of Risperidone Loaded Nanoparticles for Sustained Drug Delivery
}

\author{
Dipti Gohil*, Nirmal Shah, Rajesh A. Maheshwari \\ Department of Pharmacy, Sumandeep Vidyapeeth (Deemed to be University), Piparia, Vadodara, Gujarat, INDIA.
}

\begin{abstract}
Aim/ Background: Risperidone, an atypical antipsychotic agent, is used in the treatment of psychotic disorders due to its lower Extra Pyramidal side Effects (EPS) than conventional antipsychotics. Materials and Methods: The objective of the present investigation is to study the effect of formulation variables using $3^{2}$ factorial design; on preparation of nanoparticles to provide sustained drug release for a prolonged period of time; enhancing therapeutic efficacy by reducing dose dependent side effects. Study include formulation of nanoparticles by the nanoprecipitation method and optimization of the formulation parameters such as Amount of Polymer and Surfactant concentration as independent variables and Particle size and \% entrapment efficiency as dependent variables using design of experiment; a statistical tool. Results: Optimized formulation of nanoparticles was characterized for various physicochemical parameters. The particle size was found to be $213.3 \mathrm{~nm}$ with $82.89 \%$ drug entrapment. Conclusion: In vitro drug release study and Pharmacodynamic study portend promising results of drug delivery for longer duration.

Key words: Schizophrenia, Risperidone, Nanoparticles, $3^{2}$ factorial design, Catalepsy.
\end{abstract}

\section{INTRODUCTION}

Schizophrenia; a chronic mental disorder can be characterized by symptoms like delusions, hallucinations, disorganized speech or behavior, difficulty in concentration etc. Management of such a disease condition requires long term treatment. ${ }^{1-3}$ Long acting formulation is beneficial as an alternate treatment for patient who is non-adherent to Oral therapy. Risperidone is selective candidate drug due to lower risk of weight gain and less extrapyramidal side effects. ${ }^{47}$ Risperidone is BCS class II drug; reported to have $70 \%$ bioavailability and short halflife; 3-6 hr. Hence, long acting formulation is a need to be developed to provide controlled drug delivery which reduces dose dependent side effects. Currently, available marketed preparation of Risperidone is Solution, tablet, oral disintegrating tablet and powder for injection. ${ }^{8,9}$ An attempt has been made to develop spray dried Poly lactide co-glycolide (PLGA) nanoparticles, ${ }^{10}$ floating microparticles, ${ }^{11}$ self-nanoemulsifying drug delivery system, ${ }^{12}$ sustained release tablets, ${ }^{13}$ fast dissolving film, ${ }^{14}$ and chitosan nanoparticles. ${ }^{15}$

Due to very fine particle size, Nanoparticles are considered as potential carrier for efficient drug delivery and can be administered by various routes. Polymeric nanoparticles are more attentive due to its biodegradation, biocompatible and controlled release characteristics. ${ }^{16,17}$ Method of preparation was selected based on physicochemical properties of chosen drug and polymer. ${ }^{18-22}$ Some of the formulation variables like type and amount of polymer, type and amount of surfactant, volume of oil and aqueous phase etc. and Process variables like stirring rate, stirring time, rate of addition of oil phase etc. can affect entrapment, \% yield and drug release pattern.

The objective was to study the effect of formulation variables on preparation of
Submission Date: 16-04-2021; Revision Date: 17-05-2021; Accepted Date: 28-07-2021

DOI: 10.5530/ijper.56.1.8 Correspondence: Dr. Dipti Gohil Department of Pharmacy, Sumandeep Vidyapeeth (Deemed to be University), Piparia-391760, Vadodara, Gujarat, INDIA E-mail: diptigohil2014@ gmail.com

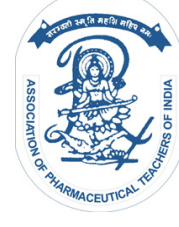

www.ijper.org 
Risperidone loaded nanoparticles using $3^{2}$ factorial design. Risperidone loaded PLGA nanoparticles are expected to reduce the frequency of administration, as well as dose and dose-dependent Extra Pyramidal side Effects (EPS).

\section{MATERIALS AND METHODS}

\section{Materials}

Risperidone and PLGA (Poly lactic acid: Glycolic acid: 75:25) were obtained as a gift sample from RPG Lifesciences, Mumbai and Purac biomaterials, Netherland; respectively. Poly Vinyl Alcohol (PVA) was obtained from Hi media, Mumbai. Other chemicals were obtained from S.D. Fine Chem, India.

\section{Methods}

Nanoparticles were prepared by Nanoprecipitation method (Sharma et al. 2014). Organic phase was prepared by dissolving weighed quantity of Risperidone and PLGA in Acetone. Aqueous phase was prepared by dissolving PVA in distilled water. Organic phase was added drop wise into aqueous phase at the rate of $1 \mathrm{ml} / \mathrm{min}$ with continuous stirring at $500 \mathrm{rpm}$ on magnetic stirrer at room temperature. Stirring was continued for $5 \mathrm{hr}$ to remove organic solvent. Resulting nanoparticulate dispersion was centrifuged at $25000 \mathrm{rpm}$ for $30 \mathrm{~min}$ at $4^{\circ} \mathrm{C}$ using cooling centrifuge (C-24 BL, Remi Instrument Pvt Ltd, Mumbai, India). Separated nanoparticles were washed twice with deionized water, following lyophilization (Heto Dry Winner, Denmark).

\section{Experimental Design}

A $3^{2}$ full factorial design was employed to study the independent and interactive effect of variables on nanoparticles at three levels i.e. low, medium and high. The design and statistical analysis were performed by Design - Expert ${ }^{\circledR}$ Software Version 10.0.1. Thirteen formulations (Table 1) of nanoparticles were prepared, which includes 9 design points and 4 centre points.

Data obtained using design expert software were subjected to fit quadratic model as shown in following equation.

$$
\mathrm{Y}=\mathrm{b}_{\mathrm{o}}+\mathrm{b}_{1} \mathrm{X}_{1}+\mathrm{b}_{2} \mathrm{X}_{2}+\mathrm{b}_{1}^{2} \mathrm{X}_{11}+\mathrm{b}_{2}^{2} \mathrm{X}_{22}+\mathrm{b}_{12} \mathrm{X}_{1} \mathrm{X}_{2}
$$

Where, b is co-efficient in Polynomial equation which shows the magnitude of effect on independent variables. A high positive or negative value of $b$ may obtain $a$ significant change in dependent variable. Checkpoint analysis was used to validate Polynomial equation. ${ }^{23-26}$ multiple regression analysis and $3 \mathrm{D}$ response surface plots were used to study the main and interaction effects of the variables on responses.

\section{Characterization}

\section{Particle size and Zeta Potential}

Particle size analysis and Zeta Potential was performed in a triplicate using a zetasizer (Nano ZS, Malvern instrument, UK). Sample was prepared by diluting dispersion with distilled water to prevent aggregation and placed in a small disposable zeta cell.

\begin{tabular}{|c|c|c|c|c|}
\hline \multirow[t]{2}{*}{ Formulation } & \multicolumn{2}{|c|}{ Independent variables } & \multicolumn{2}{|c|}{ Dependent variables } \\
\hline & $\begin{array}{c}\left(\mathrm{X}_{1}\right) \\
\text { Surfactant Concentration (\%) }\end{array}$ & $\begin{array}{c}\left(X_{2}\right) \\
\text { Amount of Polymer }(\mathrm{mg})\end{array}$ & $\begin{array}{c}\left(\mathrm{Y}_{1}\right) \\
\text { Particle Size }(\mathrm{nm})\end{array}$ & $\begin{array}{c}\left(\mathrm{Y}_{2}\right) \\
\text { \%Entrapment } \\
\text { Efficiency }\end{array}$ \\
\hline 1 & 0.5 & 50 & $184.3 \pm 1.3$ & $76.28 \pm 1.2$ \\
\hline 2 & 1 & 50 & $223.5 \pm 2.1$ & $79.38 \pm 2.3$ \\
\hline 3 & 1.5 & 50 & $259.2 \pm 2.5$ & $83.65 \pm 1.7$ \\
\hline 4 & 0.5 & 75 & $177.8 \pm 1.4$ & $78.57 \pm 2.1$ \\
\hline 5 & 1 & 75 & $213.3 \pm 3.1$ & $82.89 \pm 1.6$ \\
\hline 6 & 1.5 & 75 & $244.7 \pm 1.8$ & $84.38 \pm 1.8$ \\
\hline 7 & 0.5 & 100 & $200.5 \pm 2.5$ & $80.76 \pm 2.2$ \\
\hline 8 & 1 & 100 & $239.1 \pm 3.3$ & $84.38 \pm 2.4$ \\
\hline 9 & 1.5 & 100 & $272.4 \pm 1.9$ & $86.86 \pm 1.8$ \\
\hline 10 & 1 & 75 & $210.4 \pm 2.4$ & $81.59 \pm 1.9$ \\
\hline 11 & 1 & 75 & $216.2 \pm 1.7$ & $83.09 \pm 2.2$ \\
\hline 12 & 1 & 75 & $215.4 \pm 2.1$ & $83.14 \pm 2.4$ \\
\hline 13 & 1 & 75 & $212.6 \pm 3.1$ & $82.07 \pm 2.1$ \\
\hline
\end{tabular}




\section{Percentage Entrapment Efficiency}

Percentage entrapment efficiency of Nanoparticles was determined by dissolving $10 \mathrm{mg}$ of lyophilized nanoparticles in $10 \mathrm{~mL}$ of Acetonitrile followed by measuring the absorbance at $278 \mathrm{~nm}$ with a UV - Visible Spectrophotometer (UV - 1601, Shimadzu, Japan) after appropriate dilution with Acetonitrile.

$\% \mathrm{EE}=\frac{\text { Actual weight of drug in sample }}{\text { Theoretical weight of drug in the sample }} \times 100$

\section{\%Drug Loading}

The drug content in the Nanoparticles was determined by accurately weighing $10 \mathrm{mg}$ of lyophilized Nanoparticles and adding them in $10 \mathrm{ml}$ of Acetonitrile. Resulted dispersion was subjected to vortex and subsequently centrifugation to separate clear supernatant containing dissolved drug. Absorbance of the solution was then measured at $278 \mathrm{~nm}$ with a UV - Visible Spectrophotometer (UV - 1601, Shimadzu, Japan) after appropriate dilution with Acetonitrile.

Drug loading was calculated as follows:

$$
\text { D.L }(\%)=\mathrm{A} / \mathrm{B} \times 100
$$

Where $\mathrm{A}$ is the drug concentration in the Nanoparticles and B is the weight of NPs. Mannitol was used as cryoprotectant, which shows no interference in Risperidone peak obtained by UV-Spectrophotometric at $278 \mathrm{~nm}$.

\section{Transmission Electron Microscopy (TEM)}

Lyophilized Nanoparticles were stuck to a brass stub with double-sided adhesive tape. The stub was fixed into a sample holder and placed in the vacuum chamber of a Jeol JSM 1560 LV TEM (Jeol, Peabody, MA) and observed under low vacuum.

\section{Differential Scanning Calorimetry (DSC)}

DSC Thermogram of pure Risperidone, Polymer and drug loaded Nanoparticles was performed to study physical state of drug in Nanoparticles. Thermogram was obtained using 2910 MDSC instrument (V4.4E model, UK.). Few $\mathrm{mg}$ of sample was sealed in aluminum pan. Thermogram was recorded at heating rate of $10^{\circ} \mathrm{C} / \mathrm{min}$ with temperature range from 20 to $200^{\circ} \mathrm{C}$.

\section{In vitro drug release study}

Nanoparticles were dispersed by sonication in $1 \mathrm{~mL}$ of phosphate buffer saline ( $\mathrm{pH}$ 7.4) and placed into previously soaked dialysis bag. The bag was placed into the bottle containing $25 \mathrm{~mL}$ of release medium maintained at temperature $37 \pm 2{ }^{\circ} \mathrm{C}$ under magnetic stirring at $50 \mathrm{rpm}$. At each selected time point, an aliquot of $1 \mathrm{~mL}$ was withdrawn and the same volume was replaced by fresh release medium. The sample was analyzed for drug content using a UV-visible spectrophotometer at $279 \mathrm{~nm}$. Study was performed in triplicate. Drug release kinetic was also studied. ${ }^{27-29}$

\section{Stability study}

As per ICH guidelines, optimized formulation was stored at room temperature $\left(\sim 25^{\circ} \mathrm{C}\right)$ and refrigerator $\left(2^{\circ} \mathrm{C}\right.$ to $\left.8^{\circ} \mathrm{C}\right)$, at $75 \% \mathrm{RH}$; over a period of 3 months in stoppered glass vials. The sample was evaluated for particle size and percentage entrapment efficiency on selected point. Study was conducted in triplicate. ${ }^{30}$

\section{In vivo Catalepsy Study}

Catalepsy is a state of behavioral immobility characterized by muscle rigidity and failure to correct an externally imposed posture for a prolonged period of time. It is clinically important as similar behavioral symptoms observed with treatment of Schizophrenia like extrapyramidal side effects. Healthy (18-25 g) Swiss Albino mice were divided into three groups of six animals $(n=6)$. Saline control, Risperidone solution (5 mg/kg, i.m.) and Risperidone loaded nanoparticles were administered to respective groups. Catalepsy was evaluated at $30 \mathrm{~min}$ intervals until $240 \mathrm{~min}$. Catalepsy was assessed in the terms of the time for which the mouse remained an unusual position with both front limbs extended and resting on $4 \mathrm{~cm}$ high wooden bar $(1.0 \mathrm{~cm}$ diameter). The endpoint was considered to remove the both front limbs from the bar or if the animal moved its head in an exploratory manner. A cutoff time of $1100 \mathrm{sec}$ was applied. All the observations were made in quiet room. If the animal maintained the imposed posture for at least $20 \mathrm{sec}$, it was considered to be cataleptic and given point. For every additional $20 \mathrm{sec}$ of imposed posture, one extra point was given. The mice were evaluated twice at half an hour interval and only the greater duration of immobility was measured. ${ }^{31-33}$

\section{RESULTS \\ Experimental Design}

In present study, process variables have been kept constant and formulation variables has been optimized using statistical design. The effects of formulation variables on Nanoparticles were studied and optimized formula was proposed by design expert software upon selecting constraints. 


\section{Effect of independent variables on Particle size}

Effect of selected variables on response Particle size can be depicted by following equation.

$$
\begin{aligned}
Y_{1}= & 213.56+33.45 A+7.80 B-0.75 A B-2.27 A^{2}+ \\
& 17.78 B^{2}-0.45 A^{2} B+3.25 A^{2}
\end{aligned}
$$

Though Acetone is miscible with water, surfactant is required to reduce interfacial tension between organic phase and aqueous phase sufficiently, governing formation of fine droplet of drug in polymer solution when dropped into aqueous phase. PVA was less effective at lower concentration in reducing interfacial tension between aqueous phase and oil phase, resulted in coarser particles. At mid-level, Particle size was reduced significantly. At higher concentration of PVA, the viscosity of aqueous phase increases which leads to aggregation of droplets, consequences in the coarser particles.

Amount of polymer $\left(\mathrm{X}_{2}\right)$ had the prime influence on Particle size. With increase in amount of polymer, viscosity of oil phase increases; during emulsification this may lead to coarser droplet formation. After evaporation of organic solvent; coarser droplets resulted in formation of larger particle (Figure 1).

\section{Effect of Independent variables on \%Entrapment Efficiency}

Influence of independent variables on \%Entrapment efficiency was studied by equation 2 .

$$
\begin{aligned}
\mathrm{Y}_{2}= & 82.41+2.91 \mathrm{~A}+2.50 \mathrm{~B}-0.32 \mathrm{AB}-0.56 \mathrm{~A}^{2}- \\
& 0.15 \mathrm{~B}^{2}-0.58 \mathrm{~A}^{2} \mathrm{~B}+0.46 \mathrm{AB}^{2}
\end{aligned}
$$
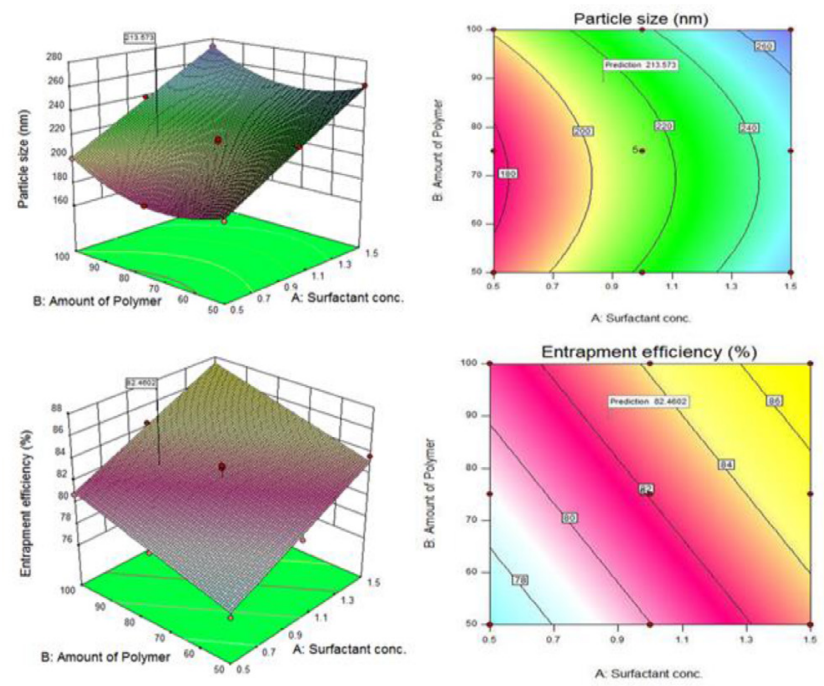

Figure 1: Contour plot and a 3D surface plot showing the effect of independent variables on Particle size and Entrapment efficiency.
Applying higher concentration of PVA in the external aqueous phase resulted in higher \% EE values. Selected drug and polymer are hydrophobic in nature; reduced interfacial tension improves the pathway for encapsulation of drug.

As the Polymer concentration increases, viscosity of oil phase also increases. Drug being more soluble in oil phase, increase in amount of polymer lead to drug enrich phase and thereby enhancing $\%$ Entrapment.

Selection of Optimized batch of nanoparticles is carried out by considering closeness of desirability factor near to 1 . The experimental value for responses of optimized formulation was found in good agreement with the predicted values and thus assured the validity of Response Surface model.

\section{Characterization}

\section{Particle size and Zeta Potential}

Particle size of optimized batch of nanoparticles was found to be $221 \mathrm{~nm}$ with very less poly dispersity index which showed presence of uniform sized particles. PLGA being negatively charged polymer imparts anionic nature to nanoparticles where zeta potential values were found to be $-25.4 \mathrm{mV}$. Nanoparticulate dispersion found to be stable due to electrostatic repulsion between similar surface charges on particles which do not allow aggregation.

\section{Drug loading}

The drug (Risperidone) loading was found to be $82.89 \% \mathrm{w} / \mathrm{w}$ for optimized batch of nanoparticles.

\section{Transmission Electron Microscopy (TEM)}

TEM micrographs (Figure 2) showed that uniform NPs were successfully prepared by using the nanoprecipitation technique. Smooth surface and spherical shape of nanoparticles were observed which can be explained by stability of emulsion that polymer had adequately formed condense matrix around the drug molecules.

\section{Differential Scanning Calorimetry (DSC)}

Risperidone and polymer showed a sharp endothermic peak at $171{ }^{\circ} \mathrm{C}$ and $59.69^{\circ} \mathrm{C}$ respectively (Figure 3) due to crystalline nature. No sharp endothermic peak observed with thermogram of nanoparticles which indicated amorphous form of drug and polymer. It can be supported by hypothesis of entrapment of drug within polymeric matrix of polymer.

\section{In vitro drug release study}

Drug release profile (Figure 4) followed biphasic pattern with an initial burst attributed to the drug associated near particles surface, followed by a linear release phase. 


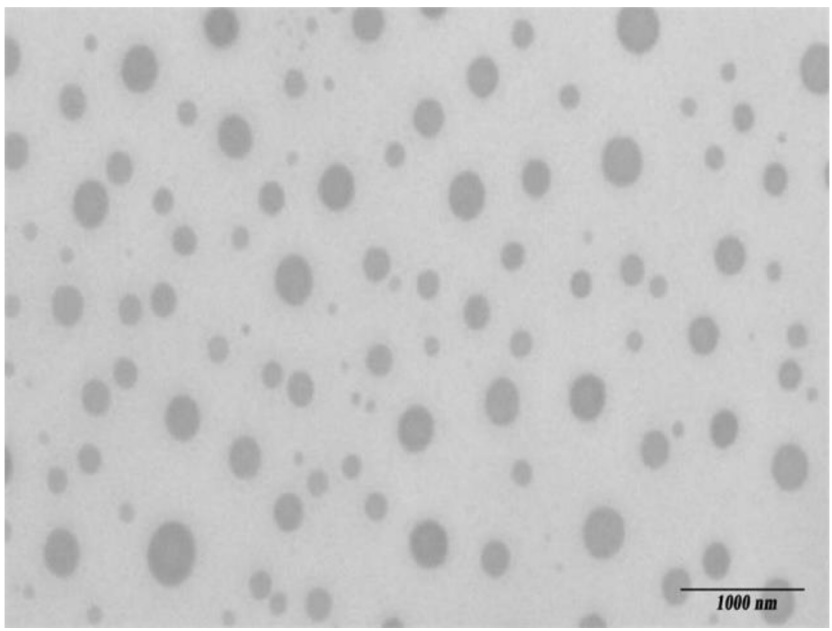

Figure 2: TEM of optimized PLGA nanoparticles.

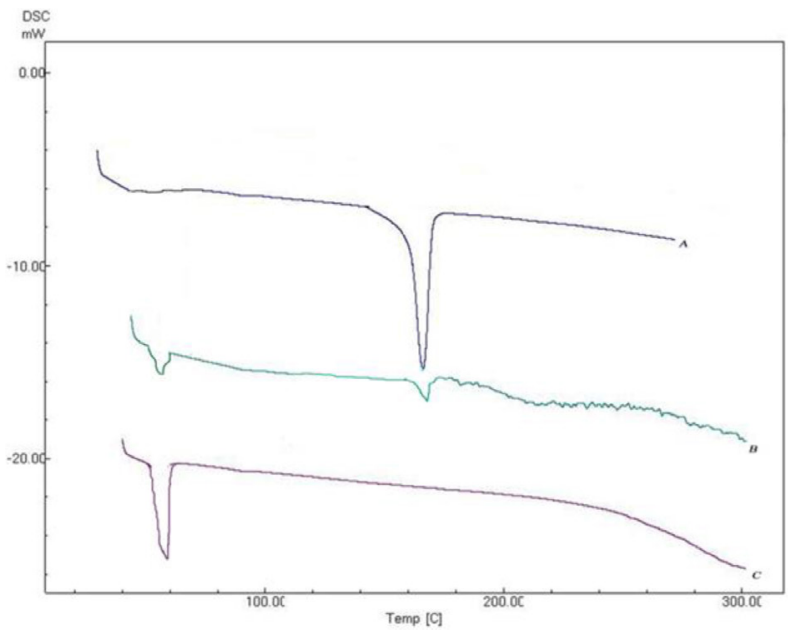

Figure 3: DSC of; (A) Risperidone (B) optimized nanoparticles, (C) PLGA (75:25).

The drug release profile confirmed to the Higuchi model $\left(R^{2}=0.9822\right)$, suggesting the drug release to be a diffusion controlled process based on the Fick's first law of diffusion in which the diffusion coefficient depends upon both the concentration of drug and the time.

\section{In vivo Catalepsy study}

In the acute study, administration of the test drugs gave cataleptic scores similar to that of the vehicle-treated group at $30 \mathrm{~min}$. However, from $60 \mathrm{~min}$ onwards, risperidone $(5.0 \mathrm{mg} / \mathrm{kg})$ and risperidone loaded PLGA nanoparticles resulted in significantly higher cataleptic scores than the vehicle-treated mice. On the other hand, risperidone loaded PLGA nanoparticles showed a marked alteration in cataleptic scores than conventional administration of risperidone group (Table 2).

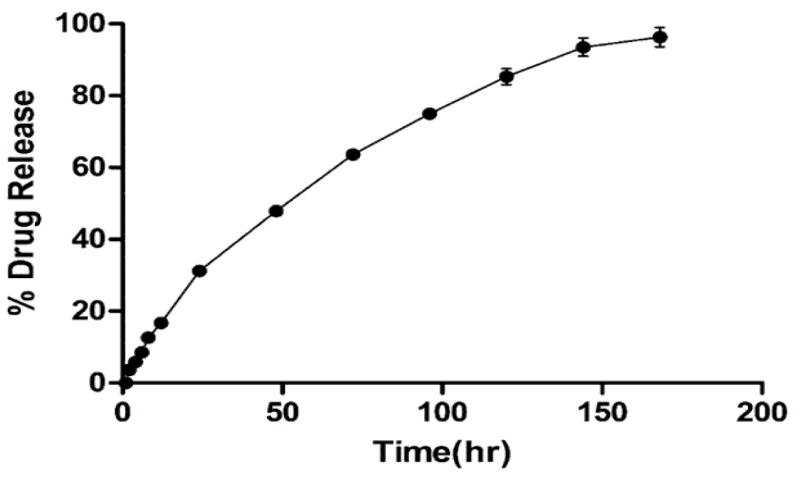

Figure 4: In vitro drug release study from nanoparticles.

\section{Stability study}

Result showed significant increase in particle size was observed during storage may be due to aggregation of nanoparticles at room temperature. \%EE of nanoparticles was also found to be significantly reduced at room temperature due to degradation of nanoparticles. Hence, it can be concluded that nanoparticles should be stored at freeze temperature $\left(2-8^{\circ} \mathrm{C}\right)$ for better stability.

\section{DISCUSSION}

The objective of Present Investigation was to study the effect of formulation variables on formulation of Risperidone loaded nanoparticles and to study the efficacy of preparation in management of Schizophrenia upon intramuscular administration. Effect of two independent variables i.e. Surfactant concentration and Amount of Polymer were studied for Particle size and $\%$ Entrapment Efficiency of nanoparticles using $3^{2}$ full factorial design. Optimized batch of nanoparticles was evaluated for various characterization parameters. Selected batch showed Particle size $213.3 \mathrm{~nm}$ with $82.8 \%$ Entrapment efficiency which is suitable for intramuscular administration.

In vitro drug release study showed extended drug release pattern for around $168 \mathrm{hr}$ and confirmed by performing Catalepsy study. Nanoparticle formulation was found to be stable with no significant change in Particle size and $\%$ Entrapment efficiency when stored at freeze temperature.

\section{CONCLUSION}

The results of theinvestigation conclusively demonstrated that nanoparticles prepared by nanoprecipitation method showed sustained release of drug over a period of $168 \mathrm{hr}$ and reduce in dose dependent side 
Table 2: Effects of Risperidone loaded PLGA nanoparticles on cataleptic scores.

\begin{tabular}{|c|c|c|c|}
\hline $\begin{array}{c}\text { Time after } \\
\text { haloperidol } \\
(\mathbf{m i n})\end{array}$ & $\begin{array}{c}\text { Control } \\
(\mathbf{1 0} \mathbf{~ m l} / \mathbf{k g}) \\
(\mathbf{a})\end{array}$ & $\begin{array}{c}\text { Risperidone } \\
\text { solution } \\
\mathbf{( 5} \mathbf{~ m g / k g )} \\
\mathbf{( b )}\end{array}$ & $\begin{array}{c}\text { Risperidone } \\
\text { loaded PLGA } \\
\text { nanoparticles (5 } \\
\mathbf{m g} / \mathbf{k g}) \\
\mathbf{( c )}\end{array}$ \\
\hline 30 & $1.0 \pm 0.74$ & $9.78 \pm 1.95$ & $8.89 \pm 1.40$ \\
\hline 60 & $1.4 \pm 0.24$ & $16.00 \pm 1.00^{* * *}$ & $14.75 \pm 1.70^{* * \$}$ \\
\hline 90 & $1.2 \pm 0.58$ & $22.75 \pm 1.81^{* * *}$ & $18.0 \pm 1.65^{* * \$}$ \\
\hline 120 & $1.3 \pm 0.84$ & $28.83 \pm 1.67^{* * *}$ & $23.65 \pm 1.90^{* * * \$}$ \\
\hline 240 & $1.0 \pm 0.78$ & $21.85 \pm 1.17^{* * * *}$ & $14.75 \pm 1.18^{* * * \$}$ \\
\hline
\end{tabular}

Values are expressed in mean \pm SEM

a vs. b, b vs. c, ${ }^{* *} p<0.01,{ }^{* * *} p<0.001,{ }^{* * * *} p<0.0001$

b vs. $c,{ }^{5} p<0.05,{ }^{55} p<0.01$

effects observed by catalepsy model; and their physical properties promise their use in the development of intramuscular sustained release injection. However, the findings of this investigation can only be settled after animal experimentation on additional animal models followed by extensive clinical study.

\section{ACKNOWLEDGEMENT}

Authors are thankful to RPG Life Science, Mumbai and Purac Biomaterials, Netherland for providing drug and excipient materials to carry out the research work.

\section{CONFLICT OF INTEREST}

The authors declare no conflict of interest.

\section{ABBREVIATIONS}

NPS: Nanoparticles; EPS: Extra Pyramidal side Effects; BCS: Biopharmaceutical Classification; PLGA: Poly lactide co-glycolide; PVA: Poly Vinyl Alcohol; 3D: Three dimensional; UV: Ultra violet; D.L.: Drug loading; TEM: Transmission Electron Microscopy; DSC: Differential Scanning Calorimetry; RH: Relative humidity; i.m.: intramuscular; mV: milli volt.

\section{REFERENCES}

1. Marder SR, Meibach RC. Risperidone in the treatment of schizophrenia. Am J Psychiatry. 1994;151(6):825-35. doi: 10.1176/ajp.151.6.825, PMID 7514366.

2. Seeman P. Dopamine receptors and the dopamine hypothesis of schizophrenia. Synapse. 1987;1(2):133-52. doi: 10.1002/syn.890010203, PMID 2905529.

3. Patel KR, Cherian J, Gohil K, Atkinson D. Schizophrenia: Overview and treatment options. P T. 2014;39(9):638-45. PMID 25210417.

4. Mathews M, Adetunji B, Mahmud J, George V, Thomas M, Joseph S. Longacting risperidone in the treatment of schizophrenia: An evidence-based approach. Psychiatry (Edgmont). 2005;2(2):36-9. PMID 21179634.
5. Muthu MS, Singh SS. Poly (D, L-lactide) nanosuspensions of risperidone for parenteral delivery: Formulation and in-vitro evaluation. Curr Drug Deliv. 2009;6(1):62-8. doi: 10.2174/156720109787048302, PMID 19418957.

6. Sussman N. Choosing an atypical antipsychotic. Int Clin Psychopharmacol. 2002;17(3);Suppl 3:S29-33. PMID 12570069.

7. McGorry PD, Cocks J, Power P, Burnett P, Harrigan S, Lambert T. Very low-dose risperidone in first-episode psychosis: a safe and effective way to initiate treatment. Schizophr Res Treatment. 2011;2011:631690. doi: 10.1155/2011/631690.

8. Grant S, Fitton A. Risperidone. A review of its pharmacology and therapeutic potential in the treatment of schizophrenia. Drugs. 1994;48(2):253-73. doi: 10.2165/00003495-199448020-00009, PMID 7527327.

9. Sharma D, Maheshwari D, Philip G, Rana R, Bhatia S, Singh M, et al. Formulation and optimization of polymeric nanoparticles for intranasal delivery of lorazepam using Box-Behnken design: In vitro and in vivo evaluation. BioMed Res Int. 2014;2014:156010. doi: 10.1155/2014/156010.

10. Panda A, Meena J, Katara R, Majumdar DK. Formulation and characterization of clozapine and risperidone co-entrapped spray-dried PLGA nanoparticles. Pharm Dev Technol. 2016;21(1):43-53. doi: 10.3109/10837450.2014.965324, PMID 25403112.

11. Ammar HO, Ghorab MM, Mahmoud AA, Noshi SH. Formulation of risperidone in floating microparticles to alleviate its extrapyramidal side effects. Future $\mathrm{J}$ Pharm Sci. 2016;2(2):43-59. doi: 10.1016/j.jjps.2016.08.001.

12. Soliman KA, Ibrahim HK, Ghorab MM. Formulation of risperidone as selfnanoemulsifying drug delivery system in form of effervescent tablets. J Dispers Sci Technol. 2012;33(8):1127-33. doi: 10.1080/01932691.2011.599235.

13. Duddelli $\mathrm{S}$, Vedavathi TA, Zu R, RSK. Formulation and evaluation of risperidone Sustained Release Tablets. Int J Pharm Biol Sci. 2013;3(3):290-98.

14. Sahu H, Alexander A, Gupta S, Yadav P, Thapa H, Banjare T, et al. Formulation and evaluation of risperidone loaded mouth-dissolving film. Res J Pharm Technol. 2018;11(7):2922-5. doi: 10.5958/0974-360X.2018.00539.5.

15. Rukmangathen R, Yallamalli IM, Yalavarthi PR. Formulation and biopharmaceutical evaluation of risperidone-loaded chitosan nanoparticles for intranasal delivery. Drug Dev Ind Pharm. 2019;45(8):1342-50. doi: 10.1080/03639045.2019.1619759, PMID 31094571.

16. Sivasankar M, Kumar BP. Role of nanoparticles in drug delivery system. Int J Res Pharm Biomed Sci. 2010;1(2):41-66.

17. Mansour HM, Sohn M, Al-Ghananeem A, DeLuca PP. Materials for pharmaceutical dosage forms: molecular pharmaceutics and controlled release drug delivery aspects. Int J Mol Sci. 2010;11(9):3298-322. doi: 10.3390/ijms11093298, PMID 20957095.

18. Minko T, Sinko P. Drug delivery systems-controlled drug release. Philadelphia: Lippincott Williams and Wilkins; 2006. p. 667-72.

19. Nokhodchi A, Raja S, Patel P, Asare-Addo K. The role of oral controlled release matrix tablets in drug delivery systems. Biolmpacts. 2012;2(4):175-87. doi: 10.5681/bi.2012.027, PMID 23678458.

20. Wilczewska AZ, Niemirowicz K, Markiewicz KH, Car H. Nanoparticles as drug delivery systems. Pharmacol Rep. 2012;64(5):1020-37. doi: 10.1016/ s1734-1140(12)70901-5, PMID 23238461.

21. Desai $D$, Shah D. Implication of nanoparticles for controlled drug delivery system. Int J Pharm Sci Res. 2013;4(7):2478-88

22. Hassan AH, Hosny KM, Murshid ZA, Alhadlaq A, Alyamani A, Naguib G. Depot injectable biodegradable nanoparticles loaded with recombinant human bone morphogenetic protein-2: preparation, characterization, and in vivo evaluation. Drug Des Devel Ther. 2015;9:3599-606. doi: 10.2147/DDDT. S79812, PMID 26203226.

23. Alzubaidi AF, El-Helw A-RM, Ahmed TA, Ahmed OA. The use of experimental design in the optimization of risperidone biodegradable nanoparticles: In vitro and in vivo study. Artif Cells Nanomed Biotechnol. 2017;45(2):313-20. doi: 10.3109/21691401.2016.1147453, PMID 26900050.

24. Mehta AK, Yadav KS, Sawant KK. Nimodipine loaded PLGA nanoparticles: Formulation optimization using factorial design, characterization and in vitro evaluation. Curr Drug Deliv. 2007;4(3):185-93. doi: 10.2174/156720107781023929, PMID 17627492.

25. Yadav KS, Sawant KK. Modified nanoprecipitation method for preparation of cytarabine-loaded PLGA nanoparticles. AAPS Pharm Sci Tech. 2010;11(3):1456-65. doi: 10.1208/s12249-010-9519-4, PMID 20842542. 
26. Patil J, Rajput R, Nemade R, Naik J. Preparation and characterization of Artemether loaded solid lipid nanoparticles: A 32 factorial design approach. Materials Technology. 2020;35(11-12):719-26. doi: 10.1080/ 10667857.2018.1475142.

27. Grabnar PA. The Comparison of Methods to assess in vitro Drug Release from Nanoparticles. Sci Pharm. 2010;78(3):679. doi: 10.3797/scipharm. cespt.8.PNM09.

28. D'Souza S. A review of in vitro drug release test methods for nano-sized dosage forms. Advances in Pharmaceutics. 2014;2014:Article ID 304757. doi: 10.1155/2014/304757.

29. Bohrey S, Chourasiya V, Pandey A. Polymeric nanoparticles containing diazepam: Preparation, optimization, characterization, in-vitro drug release and release kinetic study. Nano Converg. 2016;3(1):3. doi: 10.1186/s40580016-0061-2, PMID 28191413

30. ICH. Guideline HT. Validation Anal Proc Text Methodol. 2005;Q2(R1).

31. Hattori $\mathrm{K}$, Uchino $\mathrm{S}$, Isosaka $\mathrm{T}$, Maekawa $\mathrm{M}$, Iyo $\mathrm{M}$, Sato $\mathrm{T}$, et al. Fyn is required for haloperidol-induced catalepsy in mice. J Biol Chem. 2006;281(11):7129-35. doi: 10.1074/jbc.M511608200, PMID 16407246.

32. Kirschbaum KM, Hiemke C, Schmitt U. Rotarod impairment: Catalepsy-like screening test for antipsychotic side effects. Int J Neurosci. 2009;119(10):150922. doi: 10.1080/00207450902984002, PMID 19922371.

33. Pemminati S, Nair V, Dorababu P, Gopalakrishna HN, Pai MR. Effect of ethanolic leaf extract of $<i>$ Ocimum sanctum</i> on haloperidol-induced catalepsy in albino mice. Indian J Pharmacol. 2007;39(2):87-9. doi: 10.4103/0253-7613.32526
PICTORIAL ABSTRACT

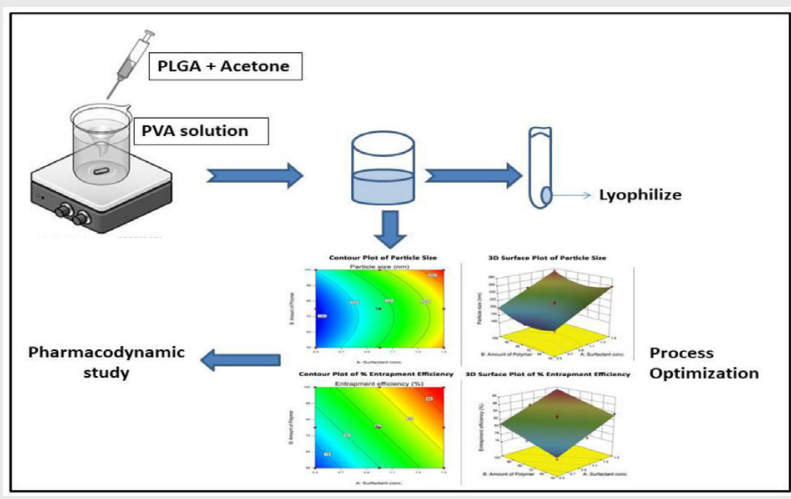

About Authors

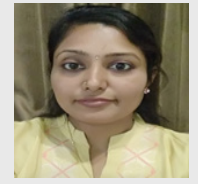

Dr. Dipti Gohil is Associate Professor in Department of Pharmacy, Sumandeep Vidyapeeth (Deemed to be University), Vadodara, India. She has guided more than 15 students at PG level. She has published a book and 2 book chapters in reputed Publishing House. Her Area of Research Interest is Formulation development, optimization and evaluation of Nanoparticulate, topical drug delivery system.

\section{SUMMARY}

From the present study, an attempt was made to curtail the problems associated with the use of currently available Risperidone preparation in management of Psychosis (Schizophrenia) by preparing Risperidone loaded nanoparticles. Nanoparticles were prepared by Nanoprecipitation method and optimized for formulation parameters using $3^{2}$ full factorial design. Prepared nanoparticles were characterized for particle size analysis, zeta potential, drug loading, Transmission electron microscopy (TEM) and Differential scanning calorimetry (DSC) study in order to check the nanoparticles dispersion suitability to be given by intramuscular injection. Optimized batch of nanoparticles showed retarded release of drug from the polymer due to reduced mobility of drug. Pharmacodynamic study confirmed extended release pattern and has reduced EPS liabilities compare to Risperidone solution. Stability study showed there was no significant increase in Particle size after reconstitution of lyophilized batch.

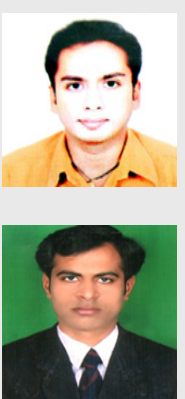

Dr. Nirmal Shah is Professor in Department of Pharmacy, Sumandeep Vidyapeeth (Deemed to be University), Vadodara, India. He has 14.5 years of Industry and Academic Experience. In addition to this, he has also published more than 80 articles in reputed National and International Journals. He was also an Editor of a book published on International platform.

Dr. Rajesh A. Maheshwari is Professor in Department of Pharmacy, Sumandeep Vidyapeeth (Deemed to be University), Vadodara, India. He has also been honored with Member of National Academy of Medical Sciences, India (MAMS) in 2017 for his contribution towards the Medical Research. In addition to this, he was also been conferred for the "Sumandeep Vidyapeeth Research Award" for two times i.e. in 2015-16 and 2018-19.

Cite this article: Gohil D, Shah N, Maheshwari RA. Effect of Formulation Variables on Fabrication of Risperidone Loaded Nanoparticles for Sustained Drug Delivery. Indian J of Pharmaceutical Education and Research. 2022;56(1):5864. 